\title{
A case series of penetrating spinal trauma: comparisons to blunt trauma, surgical indications, and outcomes
}

\author{
Kevin D. Morrow, MD, ${ }^{1}$ Adam G. Podet, MD,, Casey P. Spinelli, BS, ${ }^{2}$ \\ Lindsay M. Lasseigne, MD, ${ }^{1}$ Clifford L. Crutcher II, MD, ${ }^{1}$ Jason D. Wilson, MD,1 \\ Gabriel C. Tender, MD, ${ }^{1}$ and Anthony M. DiGiorgio, DO, MHA ${ }^{1}$ \\ 'Department of Neurosurgery and ${ }^{2}$ School of Medicine, Louisiana State University Health Sciences Center, New Orleans,
Louisiana
}

\begin{abstract}
OBJECTIVE While blunt spinal trauma accounts for the majority of spine trauma, penetrating injuries affect a substantial number of patients. The goal of this study was to examine the epidemiology of penetrating spine injuries compared with blunt injuries and review the operative interventions and outcomes in the penetrating spine injury group.
\end{abstract}

METHODS The prospectively maintained trauma database was queried for spinal fractures from 2012 to 2018. Charts from patients with penetrating spine trauma were reviewed.

RESULTS A total of 1130 patients were evaluated for traumatic spinal fractures; 154 injuries (13.6\%) were secondary to penetrating injuries. Patients with penetrating injuries were significantly younger (29.2 years vs 44.1 years, $p<0.001)$, more likely male $(87.7 \%$ vs $69.2 \%, p<0.001)$, and more commonly African American $(80.5 \%$ vs $33.3 \%, p<0.05)$. When comparing primary insurers, the penetrating group had a significantly higher percentage of patients covered by Medicaid $(60.4 \%$ vs $32.6 \%, p<0.05)$ or prison $(3.9 \%$ vs $0.1 \%, p<0.05)$ or being uninsured $(17.5 \%$ vs $10.3 \%, p<0.05)$. The penetrating group had a higher Injury Severity Score on admission (20.2 vs 15.6, $p<0.001)$ and longer hospital length of stay (20.1 days vs 10.3 days, $p<0.001)$ and were less likely to be discharged home $(51.3 \%$ vs $65.1 \%, p<0.05)$. Of the penetrating injuries, $142(92.2 \%)$ were due to firearms. Sixty-three patients (40.9\%) with penetrating injuries had a concomitant spinal cord or cauda equina injury. Of those, $44(69.8 \%)$ had an American Spinal Injury Association Impairment Scale (AIS) grade of A. Ten patients (15.9\%) improved at least 1 AIS grade, while 2 patients (3.2\%) declined at least 1 AIS grade. Nine patients with penetrating injuries underwent neurosurgical intervention: 5 for spinal instability, 4 for compressive lesions with declining neurological examination results, and 2 for infectious concerns, with some patients having multiple indications. Patients undergoing neurosurgical intervention did not show a significantly greater change in AIS grade than those who did not. No patient experienced a complication directly related to neurosurgical intervention.

CONCLUSIONS Penetrating spinal trauma affects a younger, more publicly funded cohort than blunt spinal trauma. These patients utilize more healthcare resources and are more severely injured. Surgery is undertaken for limiting progression of neurological deficit, stabilization, or infection control.

https://thejns.org/doi/abs/10.3171/2018.12.FOCUS18577

KEYWORDS penetrating spinal trauma; gunshot wound spine; blunt spinal trauma

I $\mathrm{N}$ the United States, spinal trauma represents both a major public health concern and substantial economic burden. ${ }^{8,19,25}$ Spine trauma and spinal cord injury (SCI) account for a significant source of long-term impairment and disability, affecting younger populations disproportionately. ${ }^{1,9,19}$ While blunt trauma accounts for most trau- matic spinal injuries, penetrating injuries represent higher rates of morbidity, disability, and financial burden. ${ }^{3,21}$

Literature on management of spinal trauma reflects the comparative rarity of penetrating spine data, with the studies to date focusing on the immediate management and sequelae of penetrating spine injuries. ${ }^{3,11,21}$ In contrast to the

ABBREVIATIONS AIS = American Spinal Injury Association Impairment Scale; ISS = Injury Severity Score; LOS = length of stay; MAP = mean arterial pressure; SCI = spinal cord injury.

ACCOMPANYING EDITORIAL DOI: 10.3171/2019.1.FOCUS1913.

SUBMITTED October 30, 2018. ACCEPTED December 7, 2018.

INCLUDE WHEN CITING DOI: 10.3171/2018.12.FOCUS18577. 
vast composite epidemiological data available for blunt spinal injuries that have been used to create guidelines for the classification and management of blunt spine trauma, ${ }^{30}$ data on penetrating spine trauma are relatively lacking. Consequently, there is significant variability in penetrating spinal trauma management practices with most trauma centers relying on blunt spine trauma guidelines, which may be ill-equipped for the distinct patient population and mechanism of penetrating injury. ${ }^{11,13,20}$

Our institution is an academic level 1 trauma center and safety-net hospital in the southeastern United States with a relatively high rate of penetrating spine injuries. ${ }^{27}$ The goal of this study was to examine the epidemiology of penetrating spine injuries compared with blunt injuries. Additionally, we reviewed operative interventions and outcomes in the penetrating spine injury group.

\section{Methods}

Institutional review board approval was obtained for this study. The trauma database at our institution is prospectively maintained and was queried for all traumatic spinal fractures from August 2012 to February 2018. The start date of our query was chosen to coincide with implementation of electronic medical records at our institution. Epidemiological data were collected, along with data on injury mechanism, injury intent, toxicology screen results, primary payer, Injury Severity Score (ISS), hospital length of stay (LOS), discharge location, and mortality.

Patients with penetrating spine injury were then selected for chart review. These charts were queried for neurological injuries, American Spinal Injury Association Impairment Scale (AIS) grade, vascular injury, vasopressor use, surgical intervention, and follow-up. Surgical decision-making was at the discretion of the attending neurosurgeon on call.

Statistical analysis was performed using the independent sample t-test for continuous variables and the chisquare test for nominal variables, with individual categories compared using the z-test with Bonferroni method. Statistical analyses were performed using IBM SPSS (version 24, IBM Corp.). A p value of $\leq 0.05$ was used to determine statistical significance.

\section{Results}

A total of 1130 patients were evaluated for spinal fractures during the period of our study. Of these, 154 (13.6\%) spinal traumas were secondary to penetrating injuries.

There are many significant differences between the spine trauma patients with penetrating injuries versus blunt injuries. The patients with penetrating injuries were significantly younger (mean 29.2 years vs 44.1 years, $\mathrm{p}<$ $0.001)$ and were more likely to be male $(87.7 \%$ vs $69.2 \%$, $\mathrm{p}<0.001)$. Chi-square analysis showed that the patients were significantly different when categorized by race $(\mathrm{p}$ $<0.001$ ), with more African Americans in the penetrating group $(80.5 \%$ vs $33.3 \%, \mathrm{p}<0.05)$ and a lower percentage of Caucasians ( $14.3 \%$ vs $55.5 \%, \mathrm{p}<0.05)$. Fewer patients in the penetrating group had a blood alcohol level over the legal limit $(10.4 \%$ vs $22.5 \%, \mathrm{p}<0.001)$. The groups differed significantly based on primary payer as well $(\mathrm{p}<$
0.001), with the penetrating group having a significantly higher percentage of patients covered by Medicaid $(60.4 \%$ vs $32.6 \%, \mathrm{p}<0.05)$ or prison $(3.9 \%$ vs $0.1 \%, \mathrm{p}<0.05)$ or being uninsured $(17.5 \%$ vs $10.3 \%, \mathrm{p}<0.05)$, while having lower percentages of patients covered by commercial insurance $(13.0 \%$ vs $22.2 \%, \mathrm{p}<0.05)$, Medicare $(3.2 \%$ vs $18.1 \%$, p < 0.05$)$, workers' compensation $(1.3 \%$ vs $5.6 \%$, p $<0.05)$, and liability (0\% vs $6.8 \%, \mathrm{p}<0.05)$. The patients in the penetrating group had a higher ISS on admission (mean 20.2 vs $15.6, p<0.001$ ) and a longer hospital LOS (mean 20.1 days vs 10.3 days, $\mathrm{p}<0.001$ ). Discharge location differed significantly as well $(\mathrm{p}<0.001)$, with more patients from the penetrating group being discharged to inpatient rehabilitation facilities $(27.3 \%$ vs $13.6 \%$, p < $0.05)$, other acute care facilities $(9.1 \%$ vs $3.3 \%, \mathrm{p}<0.05)$, or jail $(5.2 \%$ vs $0.9 \%, \mathrm{p}<0.05)$, while they had a lower frequency of being discharged to home $(51.3 \%$ vs $65.1 \%$, $\mathrm{p}<0.05)$ or long-term acute care $(0 \%$ vs $3.0 \%, \mathrm{p}<0.05)$. There was no significant difference in the in-hospital mortality rate $(3.9 \%$ vs $6.7 \%, \mathrm{p}>0.05)$. See Table 1 for a summary comparison of the 2 groups.

The age range of the penetrating spine injury patients was $15-65$ years, and the average was 29.2 years. Regarding race, 124 (80.5\%) were African American, 22 (14.3\%) were Caucasian, $2(1.3 \%)$ were Asian, and $6(3.9 \%)$ were other or unspecified. Sixty-three patients $(40.9 \%)$ had a concomitant SCI or cauda equina injury. Of the penetrating injuries, $142(92.2 \%)$ were due to firearms, while the remaining injuries were due to other objects. The injury intent was assault in $143(92.9 \%)$ of cases, self-inflicted in $2(1.3 \%)$, and accidental in $9(5.8 \%)$. The injury levels were distributed evenly throughout the spinal levels. Vasopressors were used to maintain elevated mean arterial pressure (MAP) goals in 23 patients (14.9\%). Two of the patients maintaining MAP goals underwent spinal surgery. Thirty-seven patients $(24.0 \%)$ also sustained a vascular injury. Nine patients $(5.8 \%)$ underwent neurosurgical intervention. See Table 2 for a summary of the demographics of the penetrating spinal trauma patients.

Sixty-three patients in the penetrating group (40.9\%) had a neurological deficit due to spinal cord or cauda equina injury. Of those, $44(69.8 \%)$ were AIS grade A. The average follow-up for the patients with neurological injury was 14.4 months, including 22 patients with no follow-up at all. Ten patients (15.9\%) improved at least 1 AIS grade, while 2 patients $(3.2 \%)$ declined at least 1 AIS grade, including 1 patient who presented as AIS grade E and declined to grade A. Patients treated with vasopressors to keep MAPs elevated did not show a greater difference in final AIS grade than those who were not $(0.36$ vs $0.24, p=$ 0.713 ). Additionally, patients undergoing neurosurgical intervention also did not show a significantly greater change in AIS grade when compared with those who did not $(0.0$ vs $0.30, p=0.476$ ).

Nine patients with penetrating injuries underwent surgery for spinal instability $(\mathrm{n}=5)$, compressive lesions with declining neurological examination findings $(n=4)$, and infectious concerns $(\mathrm{n}=2)$, with some patients having multiple indications. All patients underwent surgery in a delayed fashion ( $>24$ hours from admission). No patient experienced a complication directly related to neurosur- 
TABLE 1. Comparison between patients with penetrating and blunt spinal injuries

\begin{tabular}{|c|c|c|c|}
\hline Variable & Penetrating & Blunt & $\mathrm{p}$ Value \\
\hline No. of patients & 154 & 976 & \\
\hline Mean age, yrs & 29.2 & 44.1 & $<0.001$ \\
\hline Mean ISS & 20.2 & 15.6 & $<0.001$ \\
\hline Mean hospital LOS, days & 20.1 & 10.3 & $<0.001$ \\
\hline$\%$ male & $87.7 \%$ & $69.2 \%$ & $<0.001$ \\
\hline Race & & & $<0.001$ \\
\hline African American & $80.5 \%$ & $33.3 \%$ & * \\
\hline Caucasian & $14.3 \%$ & $55.5 \%$ & * \\
\hline Asian & $1.3 \%$ & $1.2 \%$ & \\
\hline Other & $3.9 \%$ & $9.7 \%$ & \\
\hline EtOH over limit & $10.4 \%$ & $22.5 \%$ & $<0.001$ \\
\hline Payer & & & $<0.001$ \\
\hline Liability & 0 & $6.8 \%$ & * \\
\hline VA & 0 & $2.2 \%$ & \\
\hline Commercial & $13.0 \%$ & $22.2 \%$ & * \\
\hline Uninsured & $17.5 \%$ & $10.3 \%$ & * \\
\hline Prison & $3.9 \%$ & $0.1 \%$ & * \\
\hline Medicaid & $60.4 \%$ & $32.6 \%$ & * \\
\hline Medicare & $3.2 \%$ & $18.1 \%$ & * \\
\hline Research & $0.6 \%$ & $0 \%$ & \\
\hline Workers' comp & $1.3 \%$ & $5.6 \%$ & * \\
\hline Discharge location & & & $<0.001$ \\
\hline Other acute care & $9.1 \%$ & $3.3 \%$ & * \\
\hline Left AMA & $1.9 \%$ & $1.7 \%$ & \\
\hline Deceased & $3.9 \%$ & $6.7 \%$ & \\
\hline Home & $51.3 \%$ & $65.1 \%$ & * \\
\hline Hospice & $0 \%$ & $0.3 \%$ & \\
\hline Jail & $5.2 \%$ & $0.9 \%$ & * \\
\hline LTAC & 0 & $3.0 \%$ & * \\
\hline Rehab & $27.3 \%$ & $13.6 \%$ & * \\
\hline SNF & $1.3 \%$ & $3.4 \%$ & \\
\hline
\end{tabular}

AMA = against medical advice; comp = compensation; LTAC = long-term acute care; SNF = skilled nursing facility; VA = Veterans Affairs.

The independent sample t-test was used to compare continuous variables. For nominal variables, the Pearson chi-square was used to calculate the given $p$ value

* Individual categories with statistically significant differences $(p<0.05)$ using the z-test with Bonferroni method.

gical intervention. There were no cases of postoperative CSF leakage. There were no statistically significant differences between patients who underwent surgery and those who did not regarding age, ISS, hospital LOS, change in AIS grade, or total follow-up. See Table 3 for individual descriptions of the 9 surgical patients.

The images in Fig. 1 are from the patient in case 9, who had a C2 transverse process fracture with vertebral artery injury but was neurologically intact. Because of the unilateral fracture and lack of neurological deficit, he was treated nonoperatively with a cervical collar. He presented again 2 months later with worsening neck pain and newonset bilateral upper-extremity numbness and weakness.
TABLE 2. Characteristics of patients with penetrating spine injuries

\begin{tabular}{|c|c|}
\hline Variable & Value \\
\hline No. of patients & 154 \\
\hline Mean age, yrs (range) & $29.2(15-65)$ \\
\hline Male sex & $135(87.7)$ \\
\hline \multicolumn{2}{|l|}{ Race } \\
\hline African American & $124(80.5)$ \\
\hline Caucasian & $22(14.3)$ \\
\hline Asian & $2(1.3)$ \\
\hline Other & $6(3.9)$ \\
\hline Mean ISS (range) & $20.2(4-75)$ \\
\hline $\mathrm{SCl}$ & $63(40.9)$ \\
\hline \multicolumn{2}{|l|}{ Injury level } \\
\hline Cervical & $48(21.2)$ \\
\hline Thoracic & $43(27.8)$ \\
\hline Lumbar/sacral & $44(29.2)$ \\
\hline MAP goals used & $18(11.7)$ \\
\hline Vasopressors used & $23(14.9)$ \\
\hline Vascular injury & $37(24.0)$ \\
\hline Underwent op & $9(5.8)$ \\
\hline \multicolumn{2}{|l|}{ Injury intent } \\
\hline Assault & $143(92.9)$ \\
\hline Self-inflicted & $2(1.3)$ \\
\hline Accidental & $9(5.8)$ \\
\hline Mean hospital LOS, days (range) & $20.1(1-278)$ \\
\hline
\end{tabular}

Values are presented as the number of patients (\%) unless otherwise indicated.

Repeat imaging showed ligamentous injury, spinal cord edema, and worsening alignment. Posterior stabilization was performed without complication, and he eventually regained full strength. He continues to have minor residual numbness.

\section{Discussion}

In the United States, penetrating spinal injuries are typically from gunshot wounds. The county in which our study took place has a disproportionally high number of gunshot wounds, with 45.3 per 100,000 deaths by firearm, compared to the national average of 10.18 (https:// www.cdc.gov/injury/wisqars/). This study represents one of the largest epidemiological comparisons between blunt and penetrating spinal fractures. The differences between groups are notable, with the penetrating injury patients being younger and more severely injured. There are also substantial differences regarding sex, race, and primary payers (Table 1).

Guidelines for acute care and surgical management of spine trauma are generally focused around blunt injuries. ${ }^{30}$ However, there are publications addressing some of the more pressing questions for penetrating spinal trauma. Fractures due to penetrating injury are typically stable, especially in comparison with blunt injuries. ${ }^{4,12,15,17,22,26}$ Infection rates are high, especially when combined with a 
TABLE 3. Description of the 9 surgical cases within our series of penetrating spinal injuries

\begin{tabular}{|c|c|c|c|c|c|c|c|c|}
\hline $\begin{array}{l}\text { Case } \\
\text { No. }\end{array}$ & $\begin{array}{c}\text { Age } \\
\text { (yrs), } \\
\text { Sex }\end{array}$ & $\begin{array}{l}\text { Spinal } \\
\text { Level }\end{array}$ & $\begin{array}{l}\text { Initial } \\
\text { AIS } \\
\text { Grade }\end{array}$ & Indication & Spinal Procedure Performed & Other Procedures & $\begin{array}{c}\mathrm{FU} \\
(\mathrm{mos})\end{array}$ & $\begin{array}{c}\text { Final } \\
\text { AIS } \\
\text { Grade }\end{array}$ \\
\hline 1 & $24, \mathrm{M}$ & T12-L1 & $E$ & $\begin{array}{l}\text { Declining exam due to } \\
\text { epidural hematoma }\end{array}$ & $\begin{array}{l}\text { Laminectomy \& lumbar drain } \\
\text { placement }\end{array}$ & $\begin{array}{l}\text { Exploratory laparotomy; resection of } \\
\text { colon, spleen, kidney }\end{array}$ & 5 & A \\
\hline 2 & $40, \mathrm{~F}$ & L1-4 & A & $\begin{array}{l}\text { Persistent CSF leak \& } \\
\text { meningitis }\end{array}$ & $\begin{array}{l}\text { Laminectomy, dural repair, \& } \\
\text { lumbar drain placement }\end{array}$ & None & 36 & C \\
\hline 3 & $30, M$ & L4 & $E$ & $\begin{array}{l}\text { Spinal instability \& delayed } \\
\text { neuro decline }\end{array}$ & Laminectomy \& fusion & $\begin{array}{l}\text { Exploratory laparotomy, colectomy, } \\
\text { retroperitoneal abscess drainage }\end{array}$ & 10 & $E$ \\
\hline 4 & $32, \mathrm{~F}$ & $\mathrm{C} 5$ & A & Spinal instability & $\begin{array}{l}\text { Anterior cervical corpectomy } \\
\text { \& fusion }\end{array}$ & $\begin{array}{l}\text { Neck exploration; PEG \& tracheos- } \\
\text { tomy }\end{array}$ & 1 & A \\
\hline 5 & $23, M$ & $\mathrm{C} 5$ & A & $\begin{array}{r}\text { Spinal instability \& intramed- } \\
\text { ullary spinal cord abscess }\end{array}$ & $\begin{array}{l}\text { Posterior cervical laminectomy, } \\
\text { myelotomy, washout, \& fusion }\end{array}$ & $\begin{array}{l}\text { Neck exploration, esophageal repair, } \\
\text { tracheostomy, ORIF mandible }\end{array}$ & $\begin{array}{l}\text { Lost } \\
\text { to FU }\end{array}$ & A \\
\hline 6 & $37, \mathrm{M}$ & $\mathrm{C} 7$ & A & Spinal instability & $\begin{array}{l}\text { Anterior cervical discectomy \& } \\
\text { fusion }\end{array}$ & $\begin{array}{l}\text { Exploratory laparotomy, neck explo- } \\
\text { ration, tracheostomy }\end{array}$ & 60 & A \\
\hline 7 & $20, M$ & L1-2 & A & Bullet in lumbar canal & $\begin{array}{l}\text { Minimally invasive bullet } \\
\text { removal }\end{array}$ & $\begin{array}{l}\text { Exploratory laparotomy, small bowel } \\
\text { resection, kidney resection }\end{array}$ & 4 & C \\
\hline 8 & $55, \mathrm{M}$ & L4 & D & $\begin{array}{l}\text { Declining neuro exam due to } \\
\text { compression from bullet }\end{array}$ & $\begin{array}{l}\text { Minimally invasive bullet } \\
\text { removal }\end{array}$ & None & 2 & D \\
\hline 9 & $25, M$ & $\mathrm{C} 2$ & $E$ & Spinal instability & Posterior cervical fusion & Neck exploration, PEG & 7 & $E$ \\
\hline
\end{tabular}

$\mathrm{FU}=$ follow-up; neuro = neurological; ORIF = open reduction and internal fixation; PEG = percutaneous endoscopic gastrostomy.

hollow viscus injury, ${ }^{23}$ and $7-14$ days of prophylactic antibiotic coverage can reduce the rate of infection in this population. ${ }^{4}$ In comparison to blunt SCI, a study by Readdy et al. showed that vasopressor use did not improve neurological outcomes. ${ }^{20} \mathrm{We}$ also did not find any significant improvement in neurological outcome in patients who sustained penetrating injuries and were treated with vasopressors.

The existing literature provides some guidance on surgical indication, reserving surgical intervention for progressive neurological deficit, spinal instability, or infection control. ${ }^{2-4,10-13,26-28}$ Thus, surgical intervention is largely to prevent worsening of the patient's neurological deficit and has not been shown to improve outcomes ${ }^{2,13,16,27}$ except when the bullet is in the spinal canal from T12 to L5.,24 Our data reiterate this, with our patients who underwent surgery not showing any better neurological results, on average, than those with penetrating injury who did not undergo surgery. One patient experienced a substantial decline secondary to an expanding epidural hematoma.
He remained an AIS grade A at 5 months postoperatively and was ultimately lost to follow-up. Two patients with compressive lesions in the upper lumbar spine showed improvement postoperatively.

Spinal instability is a concern with any spinal trauma. Management of blunt spinal trauma is assisted by algorithms such as the thoracolumbar injury classification ${ }^{14}$ and SLIC ${ }^{29}$ or the Denis 3-column system. ${ }^{7}$ However, due to the nature of penetrating injuries, these systems have not been shown to be applicable in penetrating spinal trauma. ${ }^{11,18}$ Five patients in our series $(3.2 \%$ of all the penetrating injuries) underwent surgery for instability, all in the cervical spine. One patient presented with delayed spinal instability that was recognized on follow-up (Fig. 1).

The neurological outcomes from penetrating spine injury are worse than those of blunt injuries. Patients with penetrating injuries are more likely to have $\mathrm{SCI},{ }^{3}$ and those with SCI are more likely to be AIS grade A., ${ }^{2,5,11,21}$ A recent SCI database review by Roach et al. showed that blunt SCIs exhibit a significantly higher rate of improve-
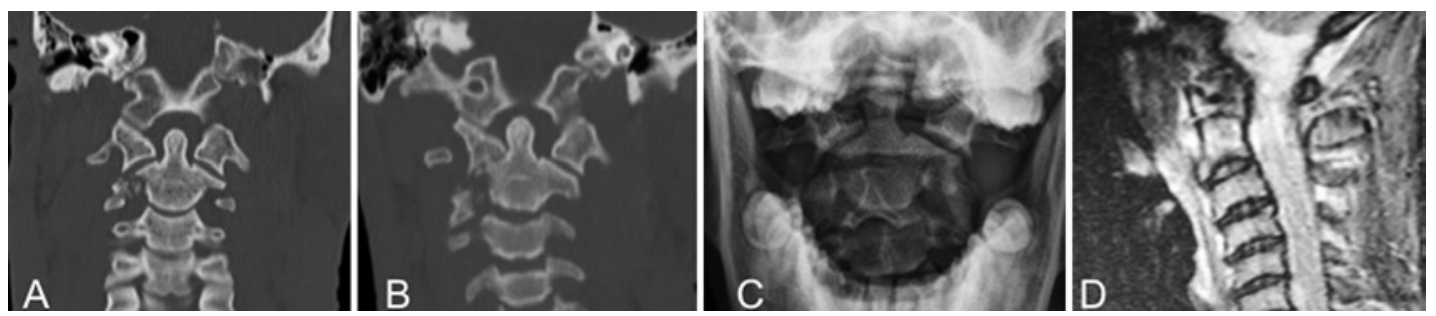

FIG. 1. Case 9. A: Noncontrast CT scan of the cervical spine, showing a comminuted fracture of the right C2 lateral mass. B: CT scan obtained 1 month after the initial presentation, showing left lateral subluxation. C: Plain radiograph revealing the subluxation. D: Significant posterior ligamentous injury is seen on STIR (short tau inversion recovery) MRI. 
ment at 1 year compared with penetrating injuries. ${ }^{21}$ Our data complement this study, showing that the penetrating spine injury patients had worse overall trauma, demonstrated by ISS. Additionally, the patients in our penetrating group had a nearly double the hospital LOS compared with the blunt injury group, as well as a reduced likelihood of being discharged home. There was no difference, however, in mortality rate during the acute inpatient stay. Our data did show that more patients in the blunt trauma group were intoxicated with alcohol, while previous studies have found that alcohol intoxication can lead to increased LOS and complications in spine trauma. ${ }^{6}$

The blunt trauma patients were, on average, less severely injured than the penetrating patients based on ISS. This is because of the large number of patients with "minor" spinal trauma, most without SCI, captured in the trauma database. For example, 401 blunt trauma patients $(41.1 \%$ of all blunt trauma) had an ISS $\leq 10$ while only 38 patients with penetrating injuries $(24.6 \%)$ had an ISS $\leq 10$. This likely explains why the blunt trauma patients had a shorter hospital stay and were more likely to be discharged home. Comparing patients with SCIs may yield different data, but that is beyond the scope of our current study.

Our study is limited by its retrospective nature. The trauma database at our institution does not collect neurological examination information outside of the Glasgow Coma Scale, so AIS grades were retrieved by chart review. Therefore, we did not have neurological outcome information for the large group of blunt injury patients for comparison. Limitations also include the geographic nature of our cohort, which does not necessarily reflect similar populations in the rest of the United States.

\section{Conclusions}

While much less common than blunt spinal trauma, penetrating spinal injuries affect a substantial proportion of patients. The patients affected by penetrating spinal trauma differ from those with blunt spinal trauma regarding age, ISS, hospital LOS, sex, race, payer, and discharge location. These patients are largely publicly funded and consume more resources than their blunt injury counterparts. We recommend against utilizing MAP goals for penetrating SCI, as these did not improve neurological outcomes and pressor use can lead to complications. The severity of injuries, combined with younger age of the patients, contributes to an expected larger overall impact of lifetime healthcare costs in the penetrating spinal injury group.

\section{References}

1. Anke AG, Stanghelle JK, Finset A, Roaldsen KS, PillgramLarsen J, Fugl-Meyer AR: Long-term prevalence of impairments and disabilities after multiple trauma. J Trauma 42:54-61, 1997

2. Beaty N, Slavin J, Diaz C, Zeleznick K, Ibrahimi D, Sansur CA: Cervical spine injury from gunshot wounds. J Neurosurg Spine 21:442-449, 2014

3. Blair JA, Possley DR, Petfield JL, Schoenfeld AJ, Lehman RA, Hsu JR: Military penetrating spine injuries compared with blunt. Spine J 12:762-768, 2012

4. Bono CM, Heary RF: Gunshot wounds to the spine. Spine J 4:230-240, 2004
5. Chittiboina P, Banerjee AD, Zhang S, Caldito G, Nanda A, Willis BK: How bullet trajectory affects outcomes of civilian gunshot injury to the spine. J Clin Neurosci 18:1630-1633, 2011

6. Crutcher CL II, Ugiliweneza B, Hodes JE, Kong M, Boakye M: Alcohol intoxication and its effects on traumatic spinal cord injury outcomes. J Neurotrauma 31:798-802, 2014

7. Denis F: The three column spine and its significance in the classification of acute thoracolumbar spinal injuries. Spine (Phila Pa 1976) 8:817-831, 1983

8. Dryden DM, Saunders LD, Jacobs P, Schopflocher DP, Rowe BH, May LA, et al: Direct health care costs after traumatic spinal cord injury. J Trauma 59:464-467, 2005

9. Heidari P, Zarei MR, Rasouli MR, Vaccaro AR, RahimiMovaghar V: Spinal fractures resulting from traumatic injuries. Chin J Traumatol 13:3-9, 2010 (Erratum in Chin J Traumatol 13:145, 2010)

10. Heiden JS, Weiss MH, Rosenberg AW, Kurze T, Apuzzo ML: Penetrating gunshot wounds of the cervical spine in civilians. Review of 38 cases. J Neurosurg 42:575-579, 1975

11. Iqbal N, Sharif S, Hafiz M, Ullah Khan A: Gunshot spinal injury: factors determining treatment and outcome. World Neurosurg 114:e706-e712, 2018

12. Jakoi A, Iorio J, Howell R, Zampini JM: Gunshot injuries of the spine. Spine J 15:2077-2085, 2015

13. Klimo P Jr, Ragel BT, Rosner M, Gluf W, McCafferty R: Can surgery improve neurological function in penetrating spinal injury? A review of the military and civilian literature and treatment recommendations for military neurosurgeons. Neurosurg Focus 28(5):E4, 2010

14. Lee JY, Vaccaro AR, Lim MR, Oner FC, Hulbert RJ, Hedlund $\mathrm{R}$, et al: Thoracolumbar injury classification and severity score: a new paradigm for the treatment of thoracolumbar spine trauma. J Orthop Sci 10:671-675, 2005

15. Lustenberger T, Talving P, Lam L, Kobayashi L, Inaba K, Plurad D, et al: Unstable cervical spine fracture after penetrating neck injury: a rare entity in an analysis of $1,069 \mathrm{pa}-$ tients. J Trauma 70:870-872, 2011

16. McCunniff PT, Ramey JS, Scott ML, Roach MJ, Vallier HA, Moore TA, et al: Operative versus nonoperative management of civilian gunshot wounds to the spinal cord: novel use of the functional independence measure for validated outcomes. World Neurosurg 106:240-246, 2017

17. Medzon R, Rothenhaus T, Bono CM, Grindlinger G, Rathlev NK: Stability of cervical spine fractures after gunshot wounds to the head and neck. Spine (Phila Pa 1976) 30:2274-2279, 2005

18. Nwosu K, Eftekhary N, McCoy E, Bhalla A, Fukunaga D, Rolfe K: Surgical management of civilian gunshot-induced spinal cord injury: is it overutilized? Spine (Phila Pa 1976) 42:E117-E124, 2017

19. Price C, Makintubee S, Herndon W, Istre GR: Epidemiology of traumatic spinal cord injury and acute hospitalization and rehabilitation charges for spinal cord injuries in Oklahoma, 1988-1990. Am J Epidemiol 139:37-47, 1994

20. Readdy WJ, Saigal R, Whetstone WD, Mefford AN, Ferguson AR, Talbott JF, et al: Failure of mean arterial pressure goals to improve outcomes following penetrating spinal cord injury. Neurosurgery 79:708-714, 2016

21. Roach MJ, Chen Y, Kelly ML: Comparing blunt and penetrating trauma in spinal cord injury: analysis of long-term functional and neurological outcomes. Top Spinal Cord Inj Rehabil 24:121-132, 2018

22. Schubl SD, Robitsek RJ, Sommerhalder C, Wilkins KJ, Klein TR, Trepeta S, et al: Cervical spine immobilization may be of value following firearm injury to the head and neck. Am J Emerg Med 34:726-729, 2016

23. Schwed AC, Plurad DS, Bricker S, Neville A, Bongard F, Putnam B, et al: Abdominal hollow viscus injuries are asso- 
ciated with spine and neurologic infections after penetrating spinal cord injuries. Am Surg 80:966-969, 2014

24. Sidhu GS, Ghag A, Prokuski V, Vaccaro AR, Radcliff KE: Civilian gunshot injuries of the spinal cord: a systematic review of the current literature. Clin Orthop Relat Res 471:3945-3955, 2013

25. Singh A, Tetreault L, Kalsi-Ryan S, Nouri A, Fehlings MG: Global prevalence and incidence of traumatic spinal cord injury. Clin Epidemiol 6:309-331, 2014

26. Syre P III, Rodriguez-Cruz L, Desai R, Greene KA, Hurst R, Schuster J, et al: Civilian gunshot wounds to the atlantoaxial spine: a report of 10 cases treated using a multidisciplinary approach. J Neurosurg Spine 19:759-766, 2013

27. Trahan J, Serban D, Tender GC: Gunshot wounds to the spine in post-Katrina New Orleans. Injury 44:1601-1606, 2013

28. Turgut M, Ozcan OE, Güçay O, Sağlam S: Civilian penetrating spinal firearm injuries of the spine. Results of surgical treatment with special attention to factors determining prognosis. Arch Orthop Trauma Surg 113:290-293, 1994

29. Vaccaro AR, Hulbert RJ, Patel AA, Fisher C, Dvorak M, Lehman RA Jr, et al: The subaxial cervical spine injury classification system: a novel approach to recognize the importance of morphology, neurology, and integrity of the discoligamentous complex. Spine (Phila Pa 1976) 32:2365-2374, 2007

30. Yue JK, Winkler EA, Rick JW, Deng H, Partow CP, Upad- hyayula PS, et al: Update on critical care for acute spinal cord injury in the setting of polytrauma. Neurosurg Focus 43(5):E19, 2017

\section{Disclosures}

The authors report no conflict of interest concerning the materials or methods used in this study or the findings specified in this paper.

\section{Author Contributions}

Conception and design: Morrow, DiGiorgio. Acquisition of data: Morrow, Podet, Spinelli, DiGiorgio. Analysis and interpretation of data: Podet, DiGiorgio. Drafting the article: Morrow, Podet, DiGiorgio. Critically revising the article: Morrow, Podet, Lasseigne, Crutcher, Wilson, Tender, DiGiorgio. Reviewed submitted version of manuscript: Morrow, Podet, Lasseigne, Crutcher, Wilson, DiGiorgio. Statistical analysis: DiGiorgio. Administrative/ technical/material support: Wilson, Tender, DiGiorgio. Study supervision: Tender, DiGiorgio.

\section{Correspondence}

Kevin D. Morrow: Louisiana State University Health Sciences Center, New Orleans, LA. kmorro@lsuhsc.edu. 